\title{
Seismic upgrading of square and rectangular RC columns using FRP wrapping
}

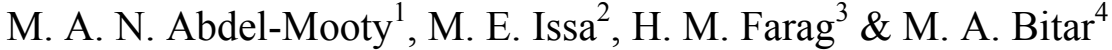 \\ ${ }^{1}$ Department of Construction Engineering, \\ American University in Cairo, Egypt \\ ${ }^{2}$ Department of Structural Engineering, Cairo University, Egypt \\ ${ }^{3}$ Department of Structural Engineering, \\ Military Technical College, Egypt \\ ${ }^{4}$ Department of Structural Engineering, \\ Military Technical College, Egypt
}

\begin{abstract}
This paper presents the results of an experimental study to evaluate the effectiveness of using FRP wrapping for repair and seismic upgrading of square and rectangular RC columns in buildings. The factors affecting the performance of FRP wrapping in rectangular columns under the action of both axial and combined axial and lateral loads are considered in this paper. These factors include the rectangularity ratio of the column cross section, the thickness of the FRP jacket, and the use of carbon verses glass FRP for column jacketing. Techniques to improve the performance of strengthening rectangular columns were also proposed and evaluated in the paper. Such techniques include rounding the sharp edges of the columns, and transferring square into circular columns using mortar. A total of fourteen half-scale reinforced concrete columns, divided into two groups, are tested in this research. The first group of columns consists of three square columns and three rectangular columns which are tested under axial loads. The second group consists of four square columns and four rectangular columns tested under combined axial and lateral loads.
\end{abstract}

Keywords: seismic upgrading, column strengthening, CFRP and GFRP.

\section{Introduction}

The use of FRP wrapping for repair, strengthening, and seismic upgrading of columns has gained increasing attention in recent years [1-3]. FRP wrapping was proposed for increasing the ductility of column under axial and axial- 
flexural loading through confinement [4-8], improving insufficient shear strength [9], and insufficient lap splice length [10]. Due to uniform confinement, FRP wrapping has been proven effective for strengthening circular columns $[4$, 10]. Other studies showed the improvement in seismic capacity of square columns wrapped with FRP jacket $[7,8]$. It was recommended that the sharp corners of the column must be rounded to avoid premature failure of the FRP jacket due to stress concentration at the corners. Studies conducted on wrapping rectangular columns showed inferior performance to that of circular and square columns $[5,11]$.

The work presented in this paper describes the first phase of a two-phase research program addressing the performance of $\mathrm{RC}$ rectangular columns strengthened using FRP wrapping jacket. The first phase is an experimental study to evaluate the effectiveness of using FRP wrapping for repair and seismic upgrading of square and rectangular RC columns in buildings. The second phase is a theoretical investigation to develop a numerical model capable to accurately predict the actual behaviour of the repair techniques. The factors affecting the performance of FRP wrapping in rectangular columns under the action of both axial and combined axial and lateral loads are considered in this paper. These factors include the rectangularity ratio of the column cross section, the thickness of the FRP jacket, and the use of carbon verses glass FRP for column jacketing. Techniques to improve the performance of strengthening rectangular columns are also proposed and evaluated in the paper. Such techniques include rounding the sharp edges of the columns and transferring square into circular columns using mortar. A total of fourteen half-scale reinforced concrete columns, divided into two groups, are tested in this research. The first group of columns consists of three square columns and three rectangular columns which are tested under axial loads. The second group consists of four square columns and four rectangular columns tested under combined axial and lateral loads.

\section{Experimental program and setup}

The test program in this research aims at studying the various parameters affecting the behaviour of reinforced concrete rectangular columns strengthened using FRP wrapping under both axial and seismic forces. These parameters include the rectangularity ratio of the column cross section, the thickness of the FRP jacket, and the use of carbon verses glass FRP for column jacketing. A total of fourteen half-scale reinforced concrete columns, divided into two groups, are tested in this research. The first group of columns, Group I, consists of three square columns; CS1, CS2 and CS3; and three rectangular columns; CR1, CR2 and CR3; which are tested under increasing axial loads to failure. The second group, Group II, consists of four square columns; CS4, CS5, CS6 and CS7; and four rectangular columns; CR4, CR5, CR6 and CR7; tested under combined axial and lateral loads. Constant axial loads, $350 \mathrm{kN}$ for square columns and 700 $\mathrm{kN}$ for rectangular columns, were applied to Group II columns during increasing cyclic lateral loading up to failure. This load level is approximately $30 \%$ of the axial load carrying capacity of the tested columns. The details of the test specimens and program are summarized in Table 1. 
Table 1: $\quad$ Summary of test program and setup.

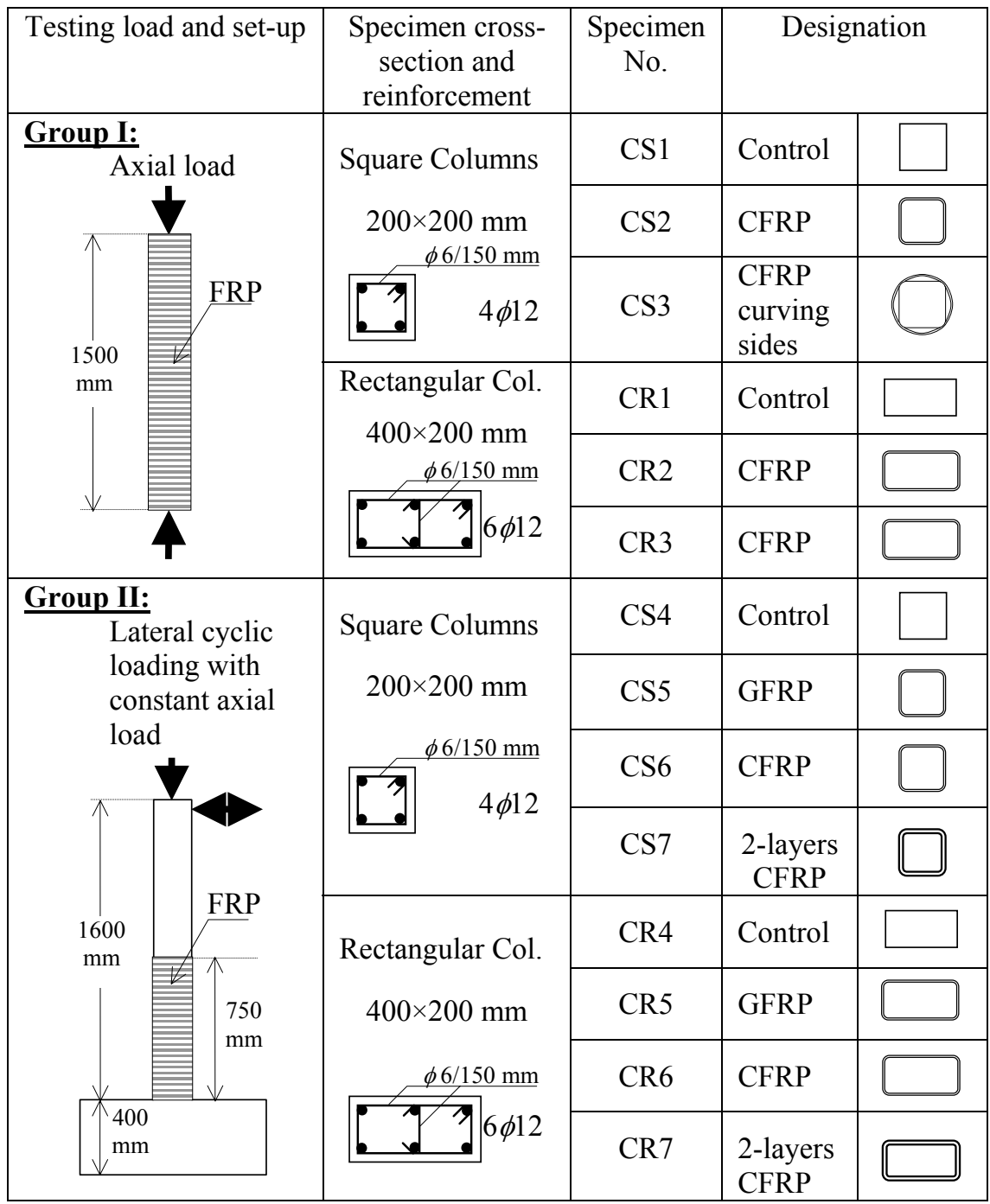

Table 2: $\quad$ Physical and mechanical properties of GFRP and CFRP.

\begin{tabular}{|l|c|c|}
\hline Property & GFRP & CFRP \\
\hline Tensile strength in fibre direction $(\mathrm{MPa})$ & 575 & 965 \\
\hline Elongation at breaking $(\%)$ & 2.2 & 1.33 \\
\hline Tensile modulus $(\mathrm{GPa})$ & 26.1 & 73 \\
\hline Nominal laminate thickness (mm) & 0.17 & 0.13 \\
\hline Fabric width (mm) & 300 & 350 \\
\hline
\end{tabular}


The average concrete strength for the test specimens after 28 days from casting is $32.5 \mathrm{MPa}$. Mild steel of diameter $6 \mathrm{~mm}$ was used for stirrups while high grade steel of diameter $12 \mathrm{~mm}$ was used for longitudinal reinforcement. Two types of fibre reinforced polymers were used for jacket wrapping of the column specimens namely Glass FRP and Carbon FRP laminates. The physical and mechanical properties for both GFRP and CFRP are displayed in Table 2.

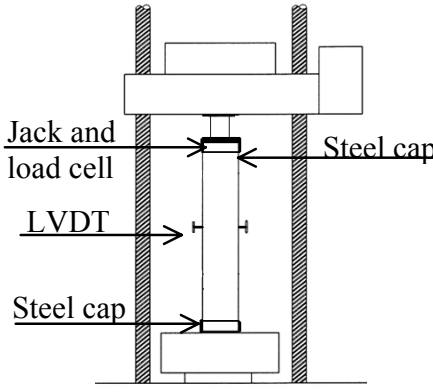

a) axial load

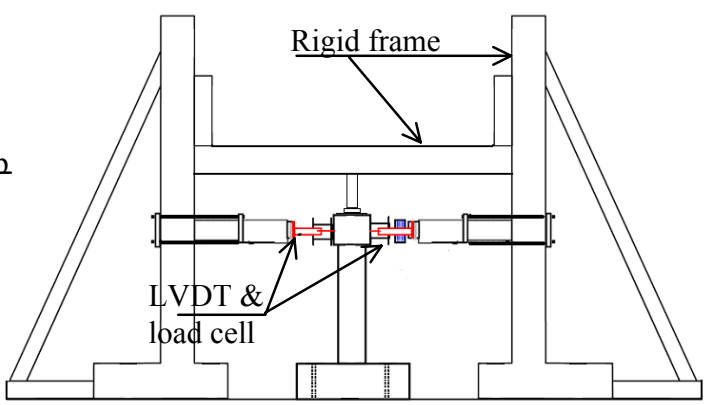

b) axial and lateral cyclic load

Figure 1: $\quad$ Schematic diagram for test set-up.

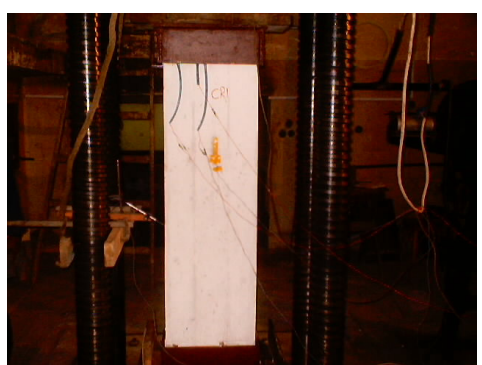

a) Control Specimen CR1 during testing

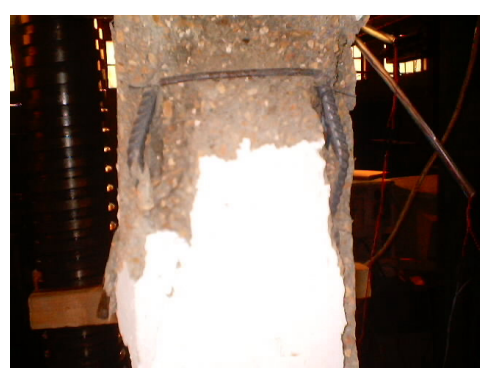

b) Failure of CR1

Figure 2: Axial load testing and failure of control specimen CR1.

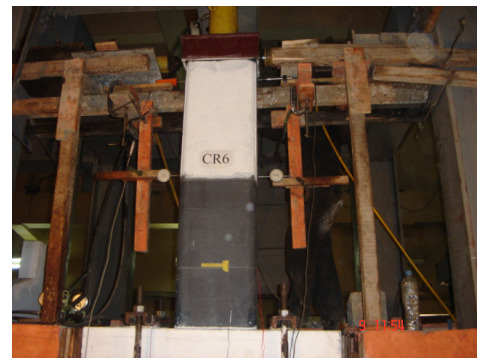

a) CR6 during testing

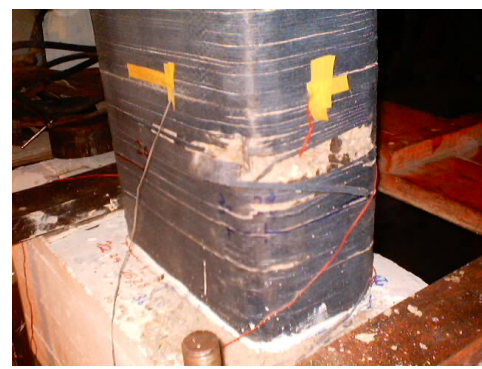

b) Failure of CR6

Figure 3: Lateral cyclic load testing and failure of specimen CS7.

Group II columns were cast integrally with a $1000 \times 400 \times 400 \mathrm{~mm}$ footing for square columns and a $1200 \times 400 \times 400 \mathrm{~mm}$ footing for rectangular columns. The footing had six bars of diameter $12 \mathrm{~mm}$ as top and bottom reinforcement with 
stirrups $10 \mathrm{~mm}$ diameter spaced at $10 \mathrm{~cm}$. The footing dimensions and reinforcement were chosen such that its deformations would not affect the measurements in the test zone.

All columns of Group II were tested under constant axial load and increasing cyclic load to failure with columns CS4 and CR4 used as reference. FRP wrapping of columns was applied within the potential plastic hinge zone of the column for a length of $750 \mathrm{~mm}$ from the footing top face. Columns CS5 and CR5 were wrapped by one layer of GFRP, Columns CS6 and CR6 were strengthened by one layer of CFRP, and Columns CS7 and CR7 were wrapped by two layers of CFRP.

The installation of the FRP jacket necessitates surface treatment. Sandpaper and sand blasting were used for concrete surface preparation before applying the epoxy resin used for installing the FRP wrapping. The sharp corners of the rectangular columns were rounded to avoid premature failure of the jacket due to stress concentration at sharp corners. Epoxy was applied uniformly on the entire face of the concrete column as well as on the FRP laminate. The fabrics were then compressed to the concrete surface with a roller. The thickness of the epoxy layer was controlled to be about $1.2 \mathrm{~mm}$. The specimens were treated at room temperature for at least 24 hours before testing.

Group I specimens were instrumented with 2 LVDT's at the mid-height to measure out of plane deformation. Strain gauges were attached to longitudinal reinforcements and the stirrups at the column mid-height to measure longitudinal and transverse strain during loading. Surface strain gauges were also mounted to the concrete surface and to the FRP jacket. Those measurements will be used for verification of the detailed numerical models developed in the second phase of this research. As for Group II specimens, LVDT's are used to measure the lateral displacement at the top and mid-height of the columns during testing. Furthermore, strain gauges are used to measure vertical and lateral strain on reinforcement and concrete and FRP surfaces near the column base. The measured load, displacements, and strains at the various locations were fed into the data acquisition system and recorded for further processing and analysis. Figure 1 shows schematic diagrams of the test set-up for Group I and Group II specimens. Figures 2 and 3 show sample specimens during testing and at failure.

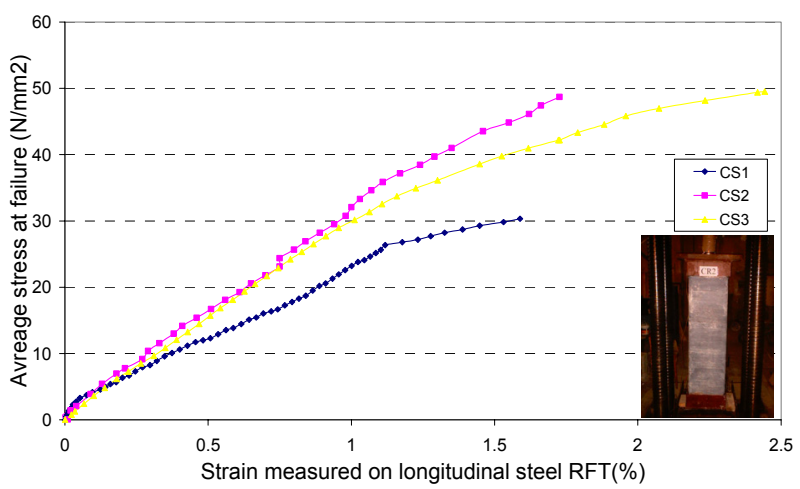

Figure 4: $\quad$ Variation of axial strain with axial stress for square columns. 
424 High Performance Structures and Materials III

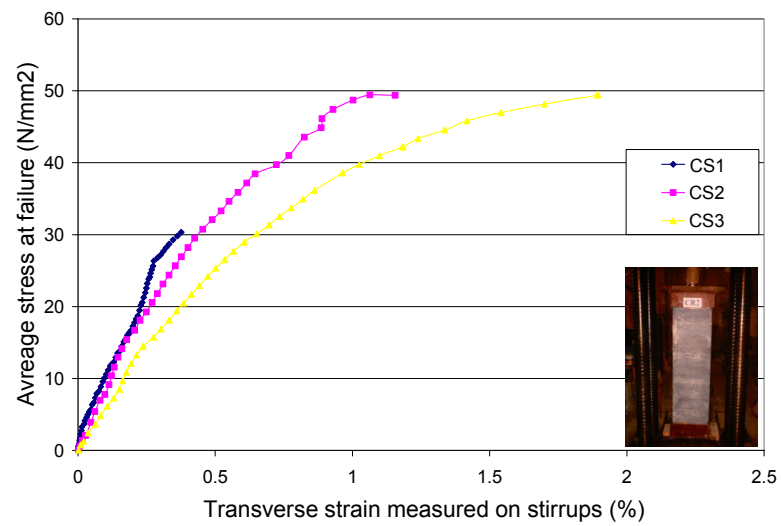

Figure 5: Variation of transverse strain with axial stress for square columns.

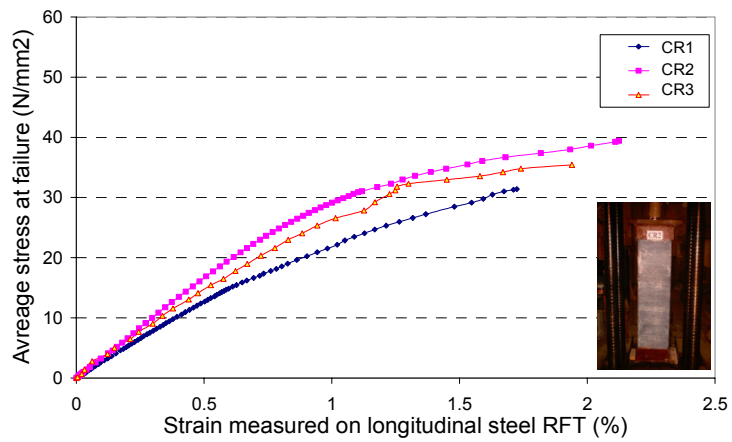

Figure 6: Variation of axial strain with axial stress for rectangular columns.

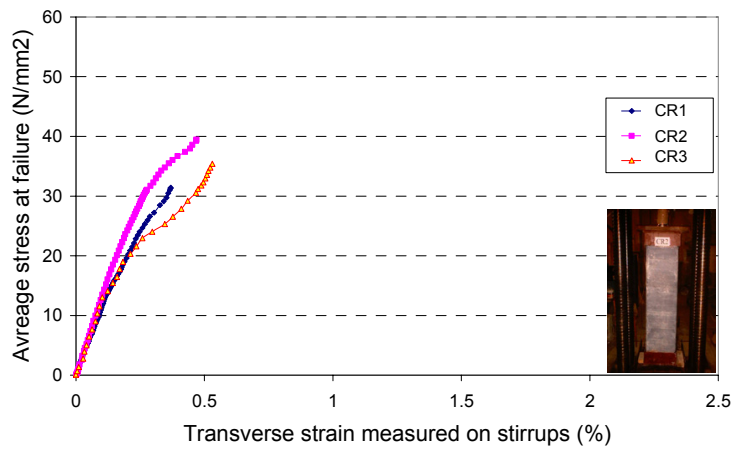

Figure 7: Variation of transverse strain with axial stress for rectangular columns. 


\section{Analysis of test results}

Group I specimens are tested under increasing axial load to failure. The square column control specimen formed inclined cracks at an average stress of $30.2 \mathrm{~N} / \mathrm{mm}^{2}$ followed by fast progressive failure in the form of falling off the concrete cover and buckling of longitudinal reinforcement. As for specimen $\mathrm{CS} 2$, and CS3, the confinement provided by the CFRP jacket delayed the failure to higher stresses values, $48.2 \mathrm{~N} / \mathrm{mm}^{2}$ for CS2 and $48.9 \mathrm{~N} / \mathrm{mm}^{2}$ for CS3. At failure the CFRP jacket was ruptured due to hoop tensile stresses after which buckling of steel longitudinal bars occurred. The rectangular specimens showed similar behaviour up to failure except that the effect of confinement due to the CFRP jacket was less pronounced. Figures 4-7 show the variation of axial strain and lateral strain with axial stress for square and rectangular column specimens respectively. Figure 8 compares the average axial stress at failure for axially loaded specimens. FRP confinement creases the ultimate capacity of axially loaded square columns by approximately $50 \%$. The confinement effect was less pronounced for rectangular columns where the increase in the ultimate capacity was about $21 \%$. Transferring square column to circular one slightly increase the average failure stress by $1.5 \%$, however the overall load capacity of the column is increased by $5.2 \%$ from $193 \mathrm{kN}$ to $203 \mathrm{kN}$ due to increasing the cross section.

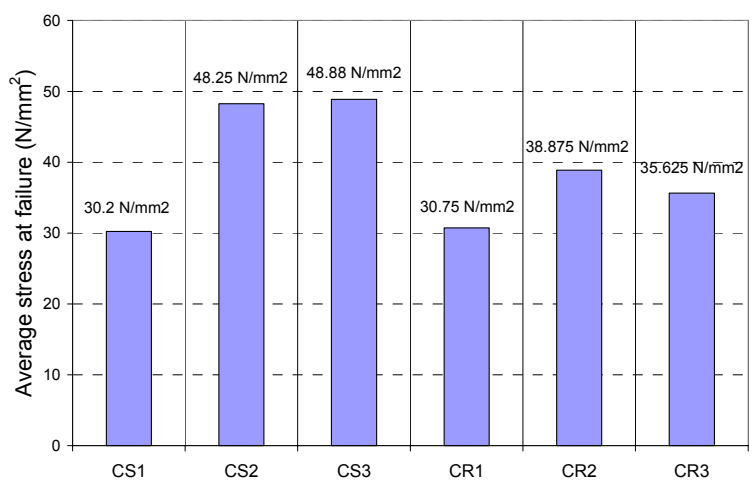

Figure 8: $\quad$ Average axial stress at failure for axially loaded columns.

Group II specimens were tested under constant axial load $(30 \%$ of the axial load capacity) and increasing cyclic load to failure. Figure 9 shows the loaddisplacement hysteresis loops for specimen CR6 during testing. All specimens in this group showed similar behaviour. As load increased cracking started first at the base, and then more cracks started to develop within approximately $450 \mathrm{~mm}$ from the base. With further increasing load, crack opened and concrete in compression crushed forming plastic hinge. Figure 10 shows the envelope for lateral load variation with lateral displacement for square specimens. The variation of lateral load with strain measured on steel stirrups for square specimens is displayed in Figure 11. The load-displacement envelope for rectangular columns is shown in Figure 12. The ultimate lateral load increased by $11 \%, 22 \%$, and $44 \%$ for square column wrapped by GFRP, CFRP and two 
CFRP layers, respectively. Similar improvements were observed for rectangular columns where lateral load increased by $12.5 \%, 25 \%$, and $33.3 \%$ for rectangular column wrapped by GFRP, CFRP and two CFRP layers, respectively. Figure 13 compares the lateral load capacity for cyclically loaded columns.

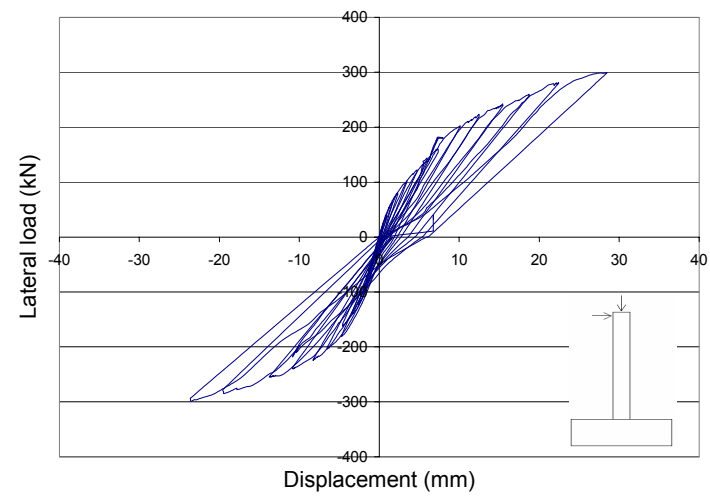

Figure 9: $\quad$ Load-displacement hysteresis loops for specimen CR6.

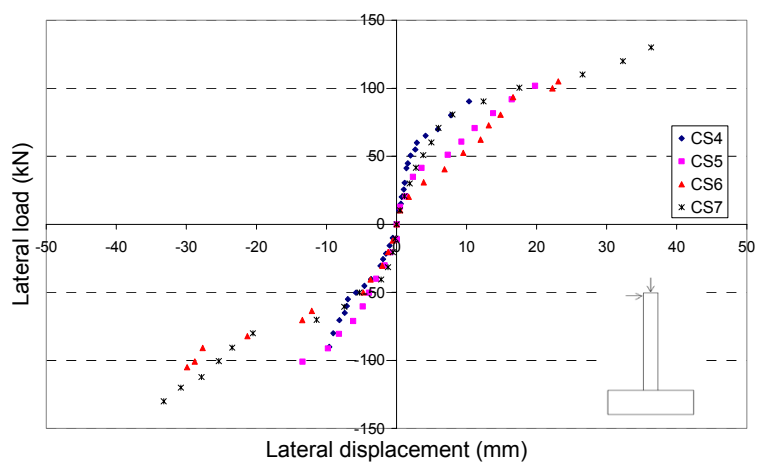

Figure 10: Lateral load vs. lateral displacement envelop for square columns.

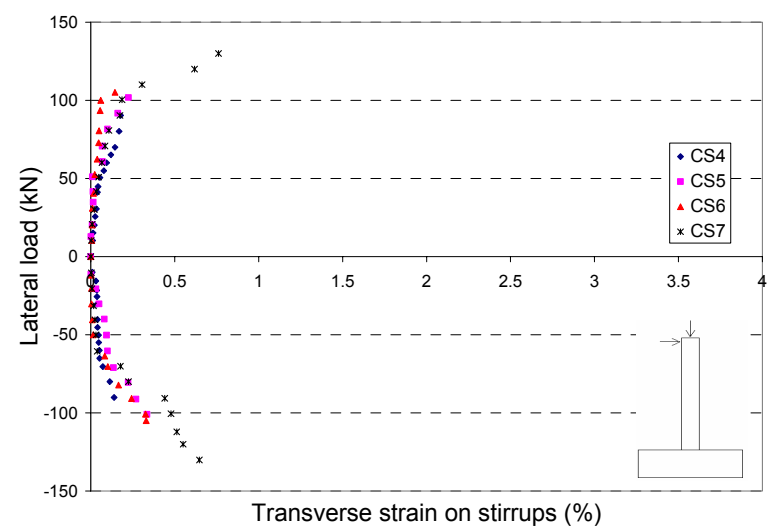

Figure 11: Lateral load vs. lateral strain on steel stirrups for square columns. 


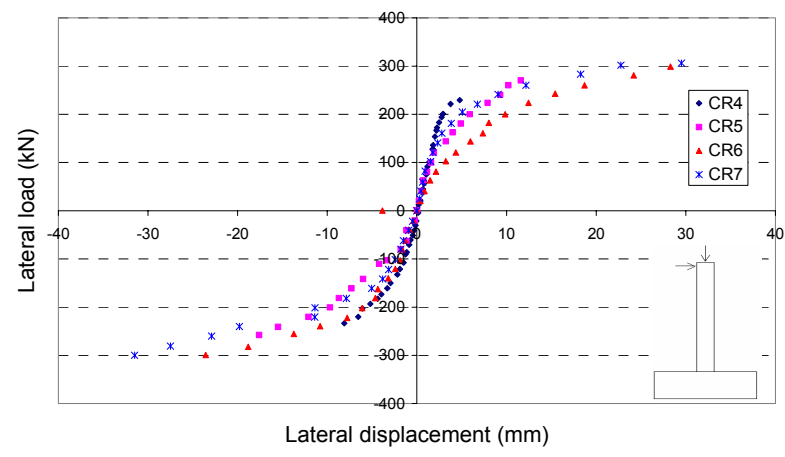

Figure 12: Lateral load vs. lateral displacement envelope for rectangular columns.

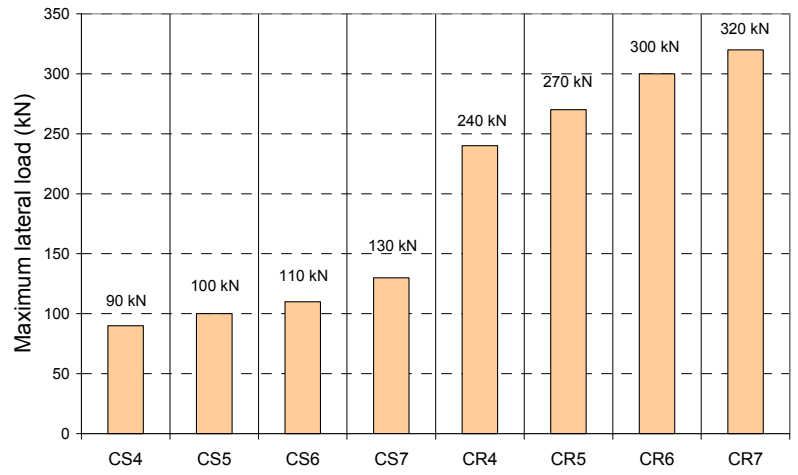

Figure 13: Ultimate lateral load for cyclic loaded specimens.

\section{Summary and conclusions}

The performance of fourteen RC square and rectangular columns strengthened using FRP wrapping jacket under axial loading and increasing lateral cyclic loading was experimentally evaluated in this paper. The loads, displacements and strains during testing were recorded for further numerical study. It was found that strengthening $\mathrm{RC}$ columns using FRP wrapping is much more efficient in square columns than in rectangular columns. Failure stresses increased due to FRP wrapping by $50 \%$ in square columns and $21 \%$ in rectangular columns. Transferring square columns to circular columns to improve FRP confinement increases the ultimate stress by only $1.5 \%$.

Group II columns subjected to combined axial and lateral loads were wrapped with FRP in the plastic hinge zone. FRP wrapping delayed concrete cracking, and increase ductility. The rupture of the FRP wrap occurs gradually with increasing load giving more warning before failure. The ultimate lateral load is increased by $11 \%, 22 \%$, and $44 \%$ for square column wrapped by GFRP, 
CFRP and two layers of CFRP respectively. Similar improvements in the lateral load capacity were observed for rectangular columns $(12.5 \%, 25 \%$, and $33.3 \%)$.

\section{References}

[1] Lehman, D.E., Gookin, S.E., Nacamuli, A.M. \& Moehle, J.P, Repair of earthquake-damaged bridge columns. ACI Structural journal, 98(2), pp. 233-242, 2001.

[2] Mosallam, A.S. (ed.). Innovative System for Seismic Repair and Rehabilitation of Structures - Design and Application, Proc. (SRRS2), Technomic Publishing co., Inc., 2000.

[3] Tan, K.H. (ed.). Fibre-Reinforced Polymer Reinforcement for Concrete Structures, Proc. of the Sixth International Symposium on FRP Reinforcement for Concrete Structures, Singapore, 8-10 July, 2003.

[4] Fam, A.Z. \& Rizkalla, S.H., Confinement model for axially loaded concrete confined by circular fiber-reinforced polymer tubes. ACI Structural journal, 98(4), pp. 451-461, 2001.

[5] Wang, Y.C. \& Restrepo, J.I., Investigation of concentrically loaded reinforced concrete columns confined with glass fibre-reinforced polymer jackets. ACI Structural journal, 98(3), pp. 377-385, 2001.

[6] Chaallal, O. \& Shahawy, M., Performance of fiber-reinforced polymerwrapped reinforcement concrete column under combined axial-flexural loading. ACI Structural journal, 97(4), pp. 659-668, 2000.

[7] Mahmoud, Kh., Fouad, E., Ramadan, M.O. \& Abd-Elalim, A., Behaviour of axially loaded square RC column confined with sandwich FRP wraps. Proc. International Conference: Future Vision and Challenges for Urban Development, Paper SG96F, Cairo, 20-22 December 2004.

[8] Allam, H.M., Strengthening of square columns by a New Technique. Proc. International Conference: Future Vision and Challenges for Urban Development, paper SG167F, Cairo, 20-22 December 2004.

[9] Haroun, M. A. \& Elsanadedy, H.M., Seismic retrofit of shear-deficient reinforced concrete bridge columns by advanced composite jackets. Proc. Structural Composite for Infrastructure Applications, Aswan, Egypt, 2002.

[10] Haroun, M.A., Mosallam, A.S., Feng, M.Q. \& Elsanadedy, H.M., Experimental Investigation of Seismic Repair and Retrofit of bridge columns by composite jackets. Journal of Reinforced Plastics and Composites, 22(14), pp. 1243-1268, 2003.

[11] Hosny A., Shahin, H. Abdelrahman, A., \& El-Afandy, T., Uniaxial tests on rectangular columns strengthened with CFRP. Proc. Structural Composite for Infrastructure Applications, Aswan, Egypt, 17-20 Dec., 2002. 